\title{
Do Iranian and Canadian Females Make Different Personal Decisions?
}

\author{
Mahin Tavakoli \\ Carleton University, Ottawa, Canada \\ Email: mtkhomei@connect.carleton.ca \\ Received April 5 ${ }^{\text {th }}$, 2011; revised July $9^{\text {th }}$, 2011; accepted September $28^{\text {th }}, 2011$
}

\begin{abstract}
This study examined cultural differences and similarities in the number and types of personal decisions made by Iranian and Canadian females. Canadians made more decisions than did Iranians, indicating that Canadians are more autonomous and independent than are Iranians. The types of decisions made more by Canadians than by Iranians illustrate that, when making decisions, Canadians use primary control (trying to change their situation) more than Iranians do, while Iranians use secondary control (trying to adjust to the situation) more than Canadians do. The results support theories of cultural differences locating Canada and Iran at opposite ends of individualism-collectivism continuum, and are consistent with the individualistic-collectivist distinctions made by Heine (2008), Savani, Markus, and Conner (2008), and Triandis (2004).
\end{abstract}

Keywords: Decision-Making; Making Choice; Iranians and Canadians; Individualism-Collectivism; Comparative Study; Cross-Cultural Study of Making Choice; Cultural Differences in Decision-Making

\section{Introduction}

In everyday life, most of us make a wide range of decisions. Our decisions can be as trivial as deciding what toothpaste to buy, which clothes to wear, what movies to watch, which club to choose for membership, and which books to read. They can also be as important as decisions about a career, finances, marriage, education, parenting, and medical or health related issues.

While there is considerable research about economic, corporate, and policy decisions (e.g., Anthony, 1999; Budescu et al., 2003; Fischhoff, 1992; Higgins, 2001; Luey, 2004; Nathan \& Hill, 1992; Shamsaie, 2001; Towner, 1975), there is almost no research about the thousands of personal decisions people make in their everyday lives. Hundreds of interesting questions about personal decisions remain to be addressed. Among them are questions about cultural differences in decisions made. One of those questions is the focus of the present article: Do people in individualistic Western cultures make more or make different personal decisions than do collectivist non-Western cultures?

\section{Features of Individualistic and Collectivist Cultures}

Individualistic cultures such as those in North America emphasize personal autonomy and choice, and social independence of the self (Iyengar \& Lepper, 1999; Vinken, Soeters, \& Ester, 2004). In contrast, collectivist cultures such as those in Asia and the Middle East emphasize conformity to the society, and encourage a strong attachment to extended families (Bond \& Smith, 1996; Triandis, 1994). While individualists have fewer rules about conforming to social norms (Vinken et al., 2004), collectivists value adherence to tradition and social norms (Hynie, n.d.), and they produce many rules, norms, and ideas about what is correct behaviour in different situations (Triandis, 1994).
Cultural theories of individualism-collectivism indicate that people in collectivist cultures tend to have larger families and closer family networks, and to foster more obedience, traditional family norms, and conformity to social norms than do people from individualistic cultures (e.g., Triandis, 1994). Choi (1995) found that Americans foster autonomous and independent behaviours of infants, and view directiveness as an indicator of parental mistrust, insensitivity, and a desire to dominate. In contrast, Koreans view infants as passive and dependent, and the norm is directive parenting. Similarly, Chinese tend to view the ideal self as embedded in interdependent social relationships rather than as an independent, self-sufficient entity; obedience and respect for others are valued more highly in China than are self-esteem or self-awareness (Chao, 1995). The Chinese believe that children learn best with instruction, and view directiveness as reflecting the notion of guan, a complex idea that means to discipline or care for and to love simultaneously (Tsang, 1998; Chao, 1995).

A study of cultural differences among American and Chinese students in conforming to parents' wishes and expectations about academic achievement revealed that Chinese students were more willing to accept their parents' wishes and cared more about fulfilling parents' expectations (Chen \& Lan, 1998). Do such cultural differences also manifest themselves in the personal decisions people make?

\section{Cultural Differences in Decision-Making}

If different cultures encourage different levels of autonomy or conformity to the social norms, how can this affect the number and nature of personal decisions? Rising interest in cultural differences in decision making, especially in Iranian-Western differences (see Dehghani et al., 2009; Ekhtiari et al., 2009) have tended to focus on decision processes, while ignoring the 
number and nature of decisions made. It seems reasonable to assume that culture will not only affect how people make decisions but also how many and what kinds of decisions they will make.

Heine (2008) speculates that culture can influence the frequency of decision-making, which he calls "making choices” (p. 259). The emphasis on autonomy among people of individualistic cultures encourages them to make more choices. While the emphasis on the conformity and adjustability to the societal norms among people of collectivist cultures leaves individuals with fewer choices to make. Heine (2008: p. 258) suggests that "Most Westerners, ..., spend a good proportion of their time obsessing about a few key choices that will have a big impact on their lives: 'What kind of job should I get?' 'Who should I marry?' 'Where should we live?' 'Should we have kids, and if so, how many and when?' these tend to be seen as personal decisions, or decisions between husband and wife. Many people take years to decide these issues... In many parts of the world, important decisions such as these are seen to reflect upon the entire extended family. And often they are not made by the individual but by his or her parents... In collectivist societies, parental decision-making is more common”.

Two studies of the influence of the culture on decisionmaking showed that Indians reported making fewer decisions than Americans (Savani \& Markus, 2006, as cited in Savani, Markus, \& Conner, 2008) and that Indians were slower than North Americans in making choices (Savani, Markus, \& Conner, 2008). If making decisions at a slower pace results in making fewer decisions in a given time period, then this result is consistent with Heine's (2008) suggestion that people in collectivist cultures make fewer choices than do people in individualist cultures. My study aimed to test this suggestion.

\section{Concept of “Control”: An Explanation for Cultural Differences in Decision-Making}

Cross-cultural researchers have introduced two concepts of primary versus secondary control, as outcomes of individualism-collectivism (Rothbaum, Weisz, \& Snyder, 1982). Primary control means changing one's situation to fit one's wishes, and it is especially seen in individualistic cultures. Secondary control means changing the self to fit the situation typically by controlling the psychological consequences of the situation, and it is especially seen in collectivist cultures (Rothbaum et al., 1982).

Research comparing the need for the two types of control among Americans and Japanese showed that Japanese showed secondary control more than Americans (Rothbaum et al., 1982). Americans not only showed primary control more often than did Japanese, but also disliked secondary control-related behaviours. Rothbaum et al. concluded that, whereas Americans construct their sense of self through social influence, Asians do so through social adjustment.

Other authors have introduced concepts similar to primary and secondary control. Primary control is equivalent to intellectual autonomy in Schwartz's (1994) list of cultural values, and is negatively related to social characteristics that he named preservation and fitting in. Triandis (2004) introduced a similar distinction called active-passive cultures. In active cultures, individuals take initiative and are competitive and action-oriented-consistent with the definition of primary control people try to change their environment to fit themselves. In passive cultures, people are more cooperative and concerned with getting along with others, and change themselves to fit their environment.

As an indication of a tie between culture, decision-making, and the concept of control, reportedly Japanese employees do not decide to change jobs as frequently as Western employees do (Weisz, Rothbaum, \& Blackburn, 1984). In Japan, employers frequently offer lifetime employment, through which the adjustment of the employees to the workplace is reinforced (Weisz et al., 1984).

The use of prevalence of primary versus secondary control in Iran has not yet been studied scientifically. There is however considerable casual observations that primary control is less frequent in Iran than Canada. Canadians appear to change their university major, partner or boy/girl friend, jobs, and their city of residence far more often than do Iranians. Moving agencies have proliferated in Canada in response to the demands of people changing their jobs or residences; such agencies are rare in Iran; an observation consistent with the literature suggesting the prevalence of primary control in North America (e.g., Rothbaum et al., 1982; Weisz et al., 1984). This paper examined such observations of decision-making and control in Iran and Canada.

\section{Decision-Making in Iran and Canada}

Research has documented the predominance of collectivism in Iran and individualism in Canada (e.g., Hofstede, 1999, 2001). In his famous “IBM Study” in 1972, Hofstede (2001) reports measures of individualism-collectivism from more than 50 countries. He found that Iran scored 41 out of 100 on individualism while Canada scored 80 . In that study, Hofstede concluded that Iran is a collective culture. This is consistent with my own observations of Iran and Canada.

Unfortunately, there has been no research in Iran since Hofstede's work examining the individualism-collectivism of the country-in part because of restrictions on social research. However, the prevalence of collectivism in contemporary Iran is supported by Iranian authors who document the large size of Iranian families, the emphasis on family, the existence of strong emotional family ties, traditional values, the emphasis on ritual, and the pressure for young people to excel academically in order to improve the image of their family (e.g., Azadarmaki \& Bahar, 2006; Hatami, 2007; Khodayarifard, Rehm, \& Khodayarifard, 2007; Mortazavi, 2006; Yeganeh, 2007). In addition, measures of trust and cooperation among in-groups and outgroups (indicants of collectivism) showed Iranians to be higher on all measures than were Americans (Buchan, Grimalda, Brewer, \& Foddy, 2007).

The shortage of empirical measurements of individualismcollectivism in the literature is not limited to Iranian culture. Surprisingly, the literature also lacks such measurements of Canadian culture. Cross-cultural researchers have mostly relied on the findings of Hofestede's original study in 1972 to support their argument that Canada is individualistic, and I shall too. I should note, however, that waves of immigrants have probably made Canada much less culturally homogeneous in the intervening years.

Based on these characteristics of Individualism-Collectivism, and on the literature that defines Iran as a collectivist culture and Canada as an individualistic culture (e.g., Hofstede, 1999, 2001; Mortazavi, 2006; Yeganeh, 2007), the present research 
tested the predictions that 1) Canadian participants will report making more decisions than will Iranians; and 2) Iranians will report using more secondary control when making decisions than will Canadians. I also compared what types of decisions Iranians and Canadians made every day.

\section{Method}

\section{Participants}

Seventy nine undergraduate students participated in this study. Iranians (31 females and 2 males) were living in Iran, and Canadians (33 females and 13 males) were living in Canada. My attempts to recruit male participants were unsuccessful. The paucity of males prompted me to exclude them from the study. All Iranians were enrolled at Azad University, Semnan Branch (a suburb of Tehran). Their age ranged from 18 to 24 years (median = 20). All Canadians were Carleton University students. Twentytwo of them were native born, and 11 were immigrants. Their age ranged from 18 to 32 years (median $=22$ ). The immigrant participants had lived in Canada between 1.5 and 29 years (median = 12); five were born in China, two in Saudi Arabia, and one each in Barbados, Guyana, Korea, and Mexico.

\section{Questionnaires}

All participants in Iran and Canada completed a Background Questionnaire (BQ) and a Making Personal Decisions (MPD) questionnaire, both developed by myself. The BQ included socio-demographic questions such as age, gender, country of birth, and language spoken at home. The MPD questionnaire listed 40 personal decision topics (choosing a university, choosing a university major, and choosing to live independent of parents, etc.) asking participants if they had ever made each decision. The 40 topics were selected from an original pool of about 100 appearing in letters to advice columnists in Iran and in Canada, because these 40 topics appeared repeatedly and covered a wide range of decisions.

\section{Procedure}

One to six Canadian participants come at the same time to a lab where the questionnaires were administered. Students completed the questionnaires in English in about 30 minutes. In Iran, a Farsi version of the questionnaires, back-translated to improve its fidelity, were administered. All the Iranian participants completed the questionnaire together during one session. It was not possible to duplicate the laboratory conditions of Carleton University because there are no labs in psychology departments in Iran.

To offset boredom and order effects (Neter, Kutner, Nachtsheim, \& Wasserman, 1995), the order of the 40 topics of advice was counterbalanced for all Canadians and Iranians. Half of the participants answered the questions about topics 1 - 40 in that order; the others answered the questions in reverse order.

\section{Results}

\section{Number of Decisions Made}

Before analysing differences in decision-making between Iranian and Canadians, I tested for differences in the number of decisions made by native-born Canadians and immigrant-Canadians. To test this, I summed the "yes” responses that each Canadian (native versus immigrant) participant gave to the question about making each of the 40 decisions. A $t$-test did not show a significant difference, $t(32)=0.71, p=0.5$. Native- born Canadians reported making an average of 32.1 of the 40 decisions; immigrant-Canadians reported an average of 31.0. There was no significant difference in these averages, $p>0.5$. I therefore combined the two groups into one that I call "Canadians”.

I then conducted another $t$-test to assess the prediction that Canadians would report making more decisions than would Iranians. The $t$-test showed a significant difference between Iranians and Canadians in the number of decisions they made, $t(57)=5.7, p=0.00$. As predicted, Iranians reported making significantly fewer decisions $(M=23.2$ out of 40$)$ than did Canadians $(M=31.4)$.

\section{Types of Decisions Made}

In order to examine cultural differences and similarities in the types of decisions made among Iranian and Canadians, and to compare Iranians and Canadians usage of primary versus secondary control, I analysed which decisions showed the greatest and smallest cultural differences. There is no useful multivariate statistical procedure for testing frequency differences in 40 dichotomous dependent variables. So instead, I calculated 40, $2 \times 2$ (culture $\times$ mention), $G$ indices as a rough index of the strength of obtained cultural differences. Such multiple indices are, as most statistics texts indicate, inferentially improper because they exploit chance in finding significance. However, the purpose in current research was not to use the $G$ s for making inferential decisions, but to use them as an indicator of the size of cultural differences, then to look for themes in the largest and smallest differences.

I counted the number of participants who said "no" and who said "yes" to each of the 40 decisions and conducted $40 \mathrm{G}$-tests. For example, in response to a question about living independent of parents, 24 Canadians and 18 Iranians said "yes" they had made the decision, and 9 Canadians and 13 Iranians said "no". I then calculated $2 \times 2$ (Culture-by-Yes/No) $G$ statistic on these four frequencies; a similar $G$ statistic was calculated on the frequencies obtained for the remaining 39 decisions. I sorted the 40 decisions from those showing the greatest $G$ values, to those showing the smallest.

Table 1 shows the 22 decisions that produced a $G$ value reaching at least a $p<0.05$ level of significance, a very rough indicant of a reliable difference between participants in two cultures. The 22 differences are ranked from largest (drinking) to smallest (choosing a career).

There are several interesting results shown in Table 1. First, it is noteworthy that all the significant differences follow a similar pattern: the percentage of Canadians making these 22 decisions is always higher than the percentage of Iranians making them. Iranians did not report making any decision more frequently than did Canadians. The greater proportion of Canadians who report making these 22 decisions supports the hypothesis that individualist Canadians would report making more decisions than would collectivist Iranians.

Second, Canadians more frequently than Iranians reported making decisions about changing their job, living independently of parents, ending their education, and breaking up or not with their partner. Iranians making less decisions about these topics suggest that Iranians more than Canadians adjusted themselves to the employers, education system, parents, and partners. 
Table 1.

Significant cultural differences in percent of participants saying yes.

\begin{tabular}{|c|c|c|}
\hline A decision about & Canadians & Iranians \\
\hline Whether or not to drink alcohol ${ }^{* *}$ & $97 \%$ & $3 \%$ \\
\hline Whether or not to smoke ${ }^{* *}$ & $94 \%$ & $6 \%$ \\
\hline Whether or not to change your job ${ }^{* *}$ & $85 \%$ & $6 \%$ \\
\hline To continue or end your education ${ }^{* *}$ & $100 \%$ & $23 \%$ \\
\hline To break up or not with your partner ${ }^{* *}$ & $82 \%$ & $13 \%$ \\
\hline To have or not have a boyfriend ${ }^{* *}$ & $94 \%$ & $52 \%$ \\
\hline Where to live ${ }^{* *}$ & $73 \%$ & $35 \%$ \\
\hline When to have children ${ }^{* *}$ & $52 \%$ & $19 \%$ \\
\hline Whether or not to lose weight ${ }^{*}$ & $97 \%$ & $65 \%$ \\
\hline To live independent of parents ${ }^{* *}$ & $73 \%$ & $42 \%$ \\
\hline How to solve your communication problems ${ }^{* *}$ & $94 \%$ & $65 \%$ \\
\hline Whether or not to bring home friends ${ }^{* *}$ & $94 \%$ & $68 \%$ \\
\hline What type of school to choose for your child ${ }^{*}$ & $24 \%$ & $3 \%$ \\
\hline How much time to spend with your family ${ }^{*}$ & $94 \%$ & $74 \%$ \\
\hline Whether or not to use cosmetics ${ }^{*}$ & $97 \%$ & $77 \%$ \\
\hline How to behave with people ${ }^{*}$ & $100 \%$ & $82 \%$ \\
\hline How to plan your schedule* & $97 \%$ & $81 \%$ \\
\hline How to spend your money ${ }^{*}$ & $100 \%$ & $84 \%$ \\
\hline Whether or not to go out with friends ${ }^{*}$ & $100 \%$ & $84 \%$ \\
\hline Which party to attend or not to attend ${ }^{*}$ & $100 \%$ & $84 \%$ \\
\hline Which films to watch or not to watch ${ }^{*}$ & $100 \%$ & $87 \%$ \\
\hline Choosing a career & $61 \%$ & $39 \%$ \\
\hline
\end{tabular}

${ }^{* *} p<0.01 .{ }^{*} p<0.05$ by $G$-test $(d f=1)$.

The third interesting feature of the results shown in Table 1 is that Iranians reported making fewer decisions even about such common matters as which film to watch or not to watch, where to live, how to plan their schedule, and how much time to spend with their family.

The lower two-thirds of Table 1 also reveals topics that produce relatively high rates of "yes" responses for Iranians. Although a greater proportion of Canadians made decisions about these topics than did Iranians, the solid majority of Iranians making most of these decisions reveals that most young Iranians do have their sphere of autonomy.

Table 2 shows the 18 decisions that produced small and statistically insignificant $G$ values. Again, they are ranked from the largest difference (vacation) to the smallest (practicing religion).

The bottom half of Table 2 shows the decision topics that exhibited the greatest similarities of percentages between cultures. These might be considered the cultural universals for the participants' age group.
Table 2.

Insignificant cultural differences in percent of participants saying yes.

\begin{tabular}{lcc}
\hline \multicolumn{1}{c}{ A decision about } & Canadians & Iranians \\
\hline Where to go for your vacation & $94 \%$ & $77 \%$ \\
What clothes to wear or not to wear & $100 \%$ & $90 \%$ \\
How to spend your free time & $100 \%$ & $90 \%$ \\
Which names to give your children & $30 \%$ & $39 \%$ \\
Whom to vote for & $79 \%$ & $87 \%$ \\
When to marry & $55 \%$ & $61 \%$ \\
Whom to marry & $61 \%$ & $68 \%$ \\
Which sport to play or not & $88 \%$ & $81 \%$ \\
What friends to choose & $100 \%$ & $94 \%$ \\
How to raise your children & $27 \%$ & $23 \%$ \\
Which books to read or not to read & $94 \%$ & $90 \%$ \\
How often to visit relatives & $85 \%$ & $81 \%$ \\
Which university major to choose & $97 \%$ & $100 \%$ \\
Which university to choose & $100 \%$ & $97 \%$ \\
Whether or not to study in another country & $45 \%$ & $42 \%$ \\
Which clothing to choose for your children & $15 \%$ & $13 \%$ \\
\hline
\end{tabular}

Not surprisingly, few participants in either culture reported making decisions about children, simply because few had children. Popular decisions showing no significant difference were largely related to personal life. Interestingly, there was no significant difference in the proportion of Canadians and Iranians who had made their own decisions about practicing their religion. In both cultures, about three-fourths of participants reported making this personal choice.

\section{Discussion}

This study tested two hypotheses about cultural differences in decision-making between Iranian and Canadian female students. Supporting my first hypothesis, the findings revealed that individualist Canadians, who have more personal autonomy, reported making more decisions than did collectivist Iranians. None of the 40 decision topics considered were made by more Iranians than Canadians. The finding is in line with Heine's (2008) speculation that an emphasis on autonomy in individualist cultures results in more decision opportunities among people of individualist cultures. It is also consistent with Savani and Markus (2006) who found Indians recalled making fewer choices during the day than did North Americans.

Examination of the 40 decision-making topics showed that a higher percentage of Canadians than Iranians reported making decisions about changing their job, continuing or ending their 
education, living independently of parents, and breaking up or not with their partner. All are topics related to changing the decision maker's situation, the defining tactic of primary control. The relative paucity of Iranians reporting these decisions supports my second hypothesis and Rothbaum et al.'s (1982) suggestion that while individualist cultures (e.g., Americans) rely on primary control and social influence, collectivist cultures (e.g., Asians) rely on secondary control and social adjustment; a concept also called preservation and fitting in (Schwartz, 1994). The finding is also consistent with Weisz et al.'s (1984) observation that collectivist Japanese change their jobs less frequently and adjust to their work-environment more frequently than do individualist North Americans.

The large cultural differences in ending or not ending one's education are also concordant with differing cultural norms about higher education. Canada has long tried to provide a university education for every Canadian who wants one. This is very different in Iran. The opportunity for higher education in Iran is severely limited, and competition for university admission is extreme. Graduates of Iranian high-schools (11th grade) who want to be considered for a university position must study for an additional year to participate in a long and difficult national university entrance exam competition called the Konkoor. If their Konkoor rank gives them the opportunity for university admission, most of the students and their parents would want to continue their education. Families place high value on higher education in Iran, and dropping out would bring shame to the family. Also, Iranian universities do not allow students to change their major unless they drop out of the program and again participate in the Konkoor. So there is little reason for young Iranian females to make their own decisions about major changes in their education activities.

Surprisingly, some Iranians reported not having made such routine decisions as which film to watch or not to watch, how to plan their own schedule, how to spend their money, whether or not to go out with friends, which party to attend or not to attend, and how to behave with people. This finding is consistent with Savani and Markus's (2006) finding that collectivist Indians identified fewer choices in their daily actions than did individualist North Americans. The finding is also consistent with Heine's (2008: p. 258) speculation that, in collectivist cultures, many of the routine decisions are made by the entire extended family and not by individuals, leaving individuals with fewer opportunities for decision-making.

Finally, the finding indicating Iranians making fewer decisions about drinking alcohol, smoking, breaking up or not breaking up with their partner, and choosing a career also reflects a common observation that the temptations, freedoms, and autonomy afforded to Canadian females are far less common for Iranian females. Most university-aged female Canadians are allowed (though perhaps not encouraged) to drink alcohol and to smoke; most are encouraged to make their own choices among a variety of jobs, and most have the autonomy to pursue intimate relationships. University-aged females in Iran have fewer opportunities to make choices about such matters. Most Iranian parents are not as tolerant as their Canadian counterparts in raising their daughters. Majority of Iranian parents restrict their daughters working in service jobs, such as jobs in retail stores or restaurants. In addition, most Iranian parents disapprove of their daughters drinking, smoking, and having boyfriends. Daughters are expected to conform to their parents' wishes. Even those who do not obey their parents would rather not talk about these topics, which are seen as the most private part of their lives, with people other than their close friends; and they likely don't feel comfortable or safe to report it when participating in research. So it is not surprising that few Iranian females would report making decisions about working, drinking, smoking, and boyfriends.

\section{Limitations and Future Research Directions}

All psychology research is influenced by the participants' characteristics and developmental stages. This research studied decision-making among female Iranian and Canadian university students. Future research should study a more diverse sample of ages, education level, gender, religion, and people from other cultures. My sample of female undergraduate university students likely would respond differently than would their parents or grandparents and than those who receive less or more education. They would also respond differently than males. Most of my participants were unmarried, did not have children, lived with parents or were financially dependent on them. All of these characteristics almost certainly influence the amount and kinds of decisions they make.

This study sampled a list of 40 decision topics, asking participants if they had ever made such decisions. Future research should sample a larger group of decision topics, and explore alternative methods for eliciting decision memories - for example, asking people to remember decisions they have made during the previous day. Research also could further explore the underlying reasons for above cultural differences and similarities in Decision-making between Iranian and Canadian females.

Despite these limitations, the study did show that cultural differences consistent with theories of individualist and collectivist culture can be reliably detected by reports of decisions people make. Further refinements of methods for collecting decision information could improve standardized indicators of cultural differences.

\section{REFERENCES}

Anthony, C. (1999). Getting married after 40: Advice \& inspiration from 100 women who found good men \& happy marriages. New York: Adams Media Corporation.

Azadarmaki, T., \& Bahar, M. (2006). Families in Iran: Changes, challenges and future. Journal of Comparative Family Studies, 37, 589-608.

Bond, R., \& Smith, P. B. (1996). Culture and conformity: A meta-analysis of studies using Asch's (1952b, 1956) line judgment task. Psychological Bulletin, 119, 111-137. doi:10.1037/0033-2909.119.1.111

Buchan, N., Grimalda, G., Brewer, M., \& Foddy, M. (2007). The impact of globalization on trust and cooperation. Unpublished preliminary report to the National Science Foundation.

Budescu, D. V., Rantilla, A. K., Yu, H.-T., \& Karelitz, T. M. (2003). The effects of asymmetry among advisors on the aggregation of their opinions. Organizational Behaviour and Human Decision Processes, 90, 178-194. doi:10.1016/S0749-5978(02)00516-2

Chao, R. (1995). Chinese and European American cultural models of the self reflected in mothers' childrearing beliefs. Ethos, 23, 328-354. doi:10.1525/eth.1995.23.3.02a00030

Chen, H., \& Lan, W. (1998). Adolescents' perceptions of their parents' academic expectations: Comparison of American, Chinese-American, and Chinese high-school students. Adolescence, 33, 385-390.

Choi, E. C. (1995). A contrast of mothering behaviours in women from Korea and the United States. Journal of Obstetric, Gynaecologic, and Neonatal Nursing, 24, 363-369. 
doi:10.1111/j.1552-6909.1995.tb02488.x

Dehghani, M., Iliev, R., Sachdeva, S., Atran, S., Ginges, J., \& Medin, D. (2009). Emerging sacred values: Iran's nuclear program. Judgment and Decision Making, 4, 530-533.

Ekhtiari, H., Jannati, A., Dehghani, M., \& Mokri, A. (2009). Prefer a cash slap in your face over credit for halva. Judgment and Decision Making, 4, 534-542.

Fischhoff, B. (1992). Giving advice: Decision theory perspectives on sexual assault. American Psychologist, 47, 577-588. doi:10.1037/0003-066X.47.4.577

Hatami, J. (2007). Creating new television audiences with new personalities in the age of globalization. Paper Presented at the AUSACE 12th Annual Convention on Communication: Cross-Road of Globalization. Dubai: United Arab Emirates.

Heine, S. J. (2008). Cultural psychology. New York: W. W. Norton \& Company.

Higgins, M. C. (2001). Changing careers: The effects of social context. Journal of Organizational Behaviour, 22, 595-618. doi:10.1002/job.104

Hofstede, G. (1999). Cultures and organizations: Software of the mind. London: McGraw-Hill.

Hofstede, G. (2001). Culture's consequences: Comparing values, behaviors, institutions, and organizations across nations. Thousand Oaks, CA: Sage Publications.

Hynie, M. (2009). From conflict to compromise: Immigrant families and the process of acculturation. URL (last checked 9 November 2009).

http://canada.metropolis.net/research-policy/litreviews/tylr_rev/tylr_r ev-08.html

Iyengar, S. S., \& Lepper, M. R. (1999). Rethinking the value of choice: A cultural perspective on intrinsic motivation. Journal of Personality and Social Psychology, 76, 349-366. doi:10.1037/0022-3514.76.3.349

Khodayarifard, M., Rehm, L. P., \& Khodayarifard, S. (2007). Psychotherapy in Iran: A case study of cognitive-behavioural family therapy for Mrs A. A. Journal of Clinical Psychology: In Session, 63, 745753.

Luey, B. (2004). Revising your dissertation: Advice from leading editors. Berkeley: University of California Press.

Mortazavi, S. (2006). The Iranian family in a context of cultural diversity. In J. Georgas, J. W. Berry, F. J. R. van de Vijver, C. Kagitcibasi, \& Y. H. Poortinga (Eds.), Families across cultures: A 30-nation psychological study (pp. 378-385). Cambridge: Cambridge University
Press. doi:10.1017/CBO9780511489822.026

Nathan, R., \& Hill, L. (1992). Career counselling. Thousand Oaks: Sage.

Neter, J., Kutner, M. H., Nachtsheim, C. J., \& Wasserman, W. (1995). Applied linear statistical models (4th ed.). Boston: McGraw-Hill.

Rothbaum, R., Weisz, J. R., \& Snyder, S. S. (1982). Changing the world and changing the self: A two-process model of perceived control. Journal of Personality and Social Psychology, 42, 5-37. doi:10.1037/0022-3514.42.1.5

Savani, K., Markus, H. R., \& Conner, A. L. (2008). Let your preference be your guide? Preferences and choices are more tightly linked for North Americans than for Indians. Journal of Personality and Social Psychology, 95, 861-876. doi:10.1037/a0011618

Schwartz, S. (1994). Beyond individualism-collectivism: New cultural dimensions of values. In U. Kim, H. C. Triandis, C. Kagitcibasi, S.-C. Choi, \& G. Yoon (Eds.), Individualism and collectivism: Theory, method, and application (pp. 81-119). Newbury Park, CA: Sage.

Shamsaie, R. K. (2001). Elementary classroom placement of multiples. Dissertation, Terre Haute: Indiana State University.

Towner, R. J. (1975). Sources of academic advice utilized by successful students when making important academic decisions. Doctoral Dissertation, Cincinnati: University of Cincinnati.

Triandis, H. C. (2004). Dimensions of culture beyond Hofestede. In H. Vinken, J. Soeters, \& P. Ester (Eds.), Comparing cultures: Dimensions of culture in a comparative Perspective (pp. 28-42). Lieden, Boston: Brill.

Triandis, H. C. (1994). Culture and social behavior. New York: McGraw-Hill.

Tsang, W. Y. (1998). The function of maternal utterances to young Hong Kong children. Unpublished Honours Thesis, Hong Kong: University of Hong Kong.

Vinken, H., Soeters, J., \& Ester, P. (2004).Cultures and dimensions: Classic perspectives and new opportunities in "dimentsionalist" cross-cultural studies. In H. Vinken, J. Soeters, \& P. Ester (Eds.), Comparing cultures: Dimensions of culture in a comparative perspective (pp. 5-27). Leieden, Boston: Brill.

Weisz, J. R., Rothbaum, F. M., \& Blackburn, T. C. (1984). Standing out and standing in: The psychology of control in America and Japan. American Psychologist, 39, 974-975. doi:10.1037/0003-066X.39.9.974

Yeganeh, H. \& Su, Z. (2007). Comprehending core cultural orientations of Iranian managers. Cross Cultural Management: An International Journal, 14, 336-353. doi:10.1108/13527600710830359 